\title{
Regressive vegetation cover status in river Kaduna catchment area Kaduna, Nigeria
}

\author{
Zaharaddeen Isa $^{1 *}$, Bala Danjuma ${ }^{2}$ \\ ${ }^{1}$ Department of Geography, Ahmadu Bello University, Zaria 810107, Nigeria \\ ${ }^{2}$ Department of Geography, Umaru Musa Yaradua University, Katsina 820241, Nigeria
}

Corresponding Author Email: isazaharaddeen@gmail.com

https://doi.org/10.18280/eesrj.050302

Received: 22 July 2018

Accepted: 28 August 2018

\section{Keywords:}

vegetation, depletion, remote sensing,

NDVI, KC, river Kaduna, regression

\begin{abstract}
It is very important to conserve the nature and composition of vegetation resources especially in an area were climate change and human activities are threatening their existence, especially Nigeria and in Particular River Kaduna Catchment Area might be one of those areas. Therefore this research aims to assess the vegetation cover status in river Kaduna catchment area. Remote sensing data and geographical information system were used to analyse the condition of vegetation in this region. Landsat imageries from 2000-2014 were used to extract NDVI, SAVI and KC was computed based on the relationship with the NDVI, to assess the vigour condition of vegetation. Linear regression analysis was computed for all the indices to determine their trend. The results of the result revealed that all the indices exhibited similar pattern of vegetation variation. It also indicate that the built up area have high NDVI and SAVI value more that the water body. The Afaka forest reserve have the highest NDVI, SAVI and $\mathrm{KC}$ value. Result indicated that the Afaka forest reserve had a healthy vegetation even though it is being threated by human explosion. The trend analysis shows a negative trend of NDVI, SAVI and KC in Catchment Area respectively. It can be conclude that NDVI, SAVI and Kc showed a spatial and temporal variability in Middle Kaduna River Catchment area. The vegetation condition varied from one region to another This result shows a depletion of the vegetation as a consequence of human activities particularly fuel wood, cultivation for agricultural purposes and deforestation. It also has implication for global carbon dioxide loading and temperature.
\end{abstract}

\section{INTRODUCTION}

Nigeria is endowed with potential for vegetation $[4,12,16]$. This natural resources is being threated by climate change and human activities, include deforestation, because of urban development (i.e. land use/ land cover changes) [21, 28]. This has over the years proven to be the cause of the major decline in vegetation cover in the region [12]. The consumption of fuel wood is undoubtedly high in the region as noted by [4]. It reported that vegetation of Kaduna state is declining, a notable example is Kagoro forest [5] and Afaka forest reserve [25].

For example: [6], the environmental resources over exploited in Nigeria without adequate replacement is vegetation particularly trees. The fuel wood is the only means of domestic fire in the desert - prone states leading to desertification as other sources of domestic fire are almost not in use [27]. This has might result from uncontrolled population explosion especially in the developing countries, the need and struggle for survival as well as the quest for more comfort. This had been confirmed by [24] that daily average of 91.9 tons of wood is harvested from the forest and transported into Kaduna through various classes of vehicles. No specific scientific method of harvesting is in place and the rate of regeneration and/or replacement planting is far below the rate of harvesting. Expected that in no time, the Afaka forest may disappear with enormous consequences on the environment.

According to [21] in the inner core city of Kaduna and its environs there is intensive conversion of vegetation to build up area. Most of these area mention before are part of Middle river Kaduna catchment area. Unplanned urbanisation and its subsequent impacts on natural resources like forest and vegetation has urged the necessity of scientific investigation and its accountability study of our natural assets.

Considering the important Vegetation in the maintenance of an attractive environment, provision of opportunity for relatively intense outdoor recreation, provision of habitat for wildlife, watershed function, general conservation including minimization of soil erosion and production of wood [5]. And serves as effective sink for carbon dioxide [5]. It has major influence on the hydrology of surface and ground water [20]. And depletion of it has led to changes in the water balance in any catchments which have led to land and river salinization, changed flood frequency and flow regime, [13], reduced evapotranspiration [7]. Therefore, Assessing and monitoring vegetation condition is a key requirement for global change research. Classifying and mapping vegetation is an important task for managing natural resources, as it provides a base for all living beings [9].

The role of remote sensing (RS) and Geographical Information System (GIS) technology in vegetation analysis is to support plans for sustainable development. It has become the most effective approach in monitoring, classifying and observing the condition of vegetation properties [2]. These properties have been defined using vegetation indices, primarily calculated using band reflectance of Red and NIR, these include Normalized Difference Vegetation Index 
(NDVI), Soil Adjusted Vegetation Index (SAVI) introduce by [26] and Crop coefficient (KC) which is a dimensionless number (usually between 0.1 and 1.2) which used to calculate actual evapotranspiration (ETc). Kc can be estimated using satellite data through the relation between $\mathrm{Kc}$ and Normalize Difference Vegetation Index NDVI which was used by [11] and evaluated by [10]. These indices have been used to monitor crop condition and forecast yield as well as production in many countries of the world [23]. Also they are representative of plant's photosynthetic efficiency, which have been widely used for presenting vegetation cover from different data source [23]. While Crop coefficients is primarily dependant on the dynamics of canopies, light absorption by the canopy, canopy roughness, which affects turbulence, plant physiology, leaf age and surface wetness [15]. As plant canopy develops, the ratio of transpiration to evapotranspiration increases, until most of the evapotranspiration comes from transpiration, and soil evaporation is a minor component [7].

Therefore, the objective of this study is to assess the condition and the spatio-temporal variation of vegetation by the use of remote sensing data and vegetation indices such as normalized difference vegetation index (NDVI), soil adjusted vegetation index (SAVI) and crop coefficient (KC) in Middle River Kaduna catchment area, Nigeria.

\section{METHODOLOGY}

The The study area lies between latitudes $10.245^{\circ} \mathrm{N}$ and $10.808^{\circ} \mathrm{N}$ and longitude $7.021^{\circ} \mathrm{E}$ and $7.786^{\circ} \mathrm{E}$ (Figure 1). The Middle Kaduna River Catchment (Figure 1) is within the highland climatic zone of Nigeria with an Altitude of $591 \mathrm{~m}$. The mean evaporation loss annually is $2448 \mathrm{~mm}$. It is drained by River Kaduna and its major tributaries; Rivers Rigachikun, Ruza and Romi. Kaduna River takes its source from Jos Plateau state and flows for about $210 \mathrm{~km}$ to Kaduna Town. It crosses the town, dividing it into North and South areas. The River flows beyond Kaduna for about $100 \mathrm{~km}$ into the Shiroro Dam and continues until it finally discharges into the River Niger about 200km from Shiroro dam [8].
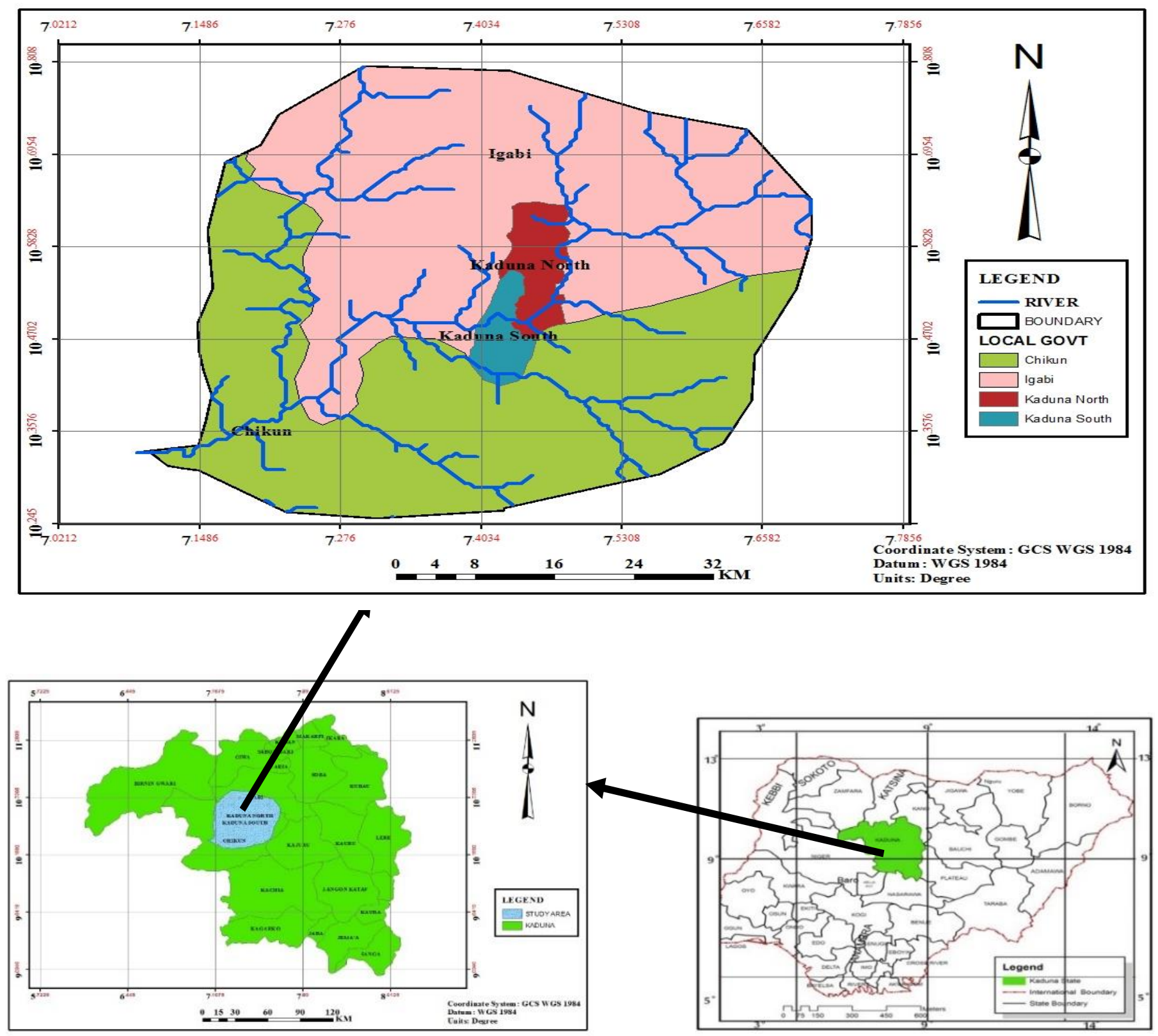

Figure 1. Map of the Lower River Kaduna Catchment Area 


\subsection{Remote sensing data}

Table 1. Characteristic of Satellite Imageries

\begin{tabular}{cccc}
\hline Data detail & Band & Resolution & Season of data taking \\
\hline Landsat7 ETM+ & 8 & $30 \mathrm{~m}$ & Dry Season \\
\hline Landsat8 OLS & 11 & $30 \mathrm{~m}$ & Dry season \\
\hline Sour
\end{tabular}

Source: NASA Handbook, (2015)

Satellite imageries of the study area (Landsat imageries) for fourteen epoch (2000 to 2014) were obtained from USGS website (www.earthexplorer.usgs.gov.org). Although, some of the image have cloud cover for example 2010. Therefore, those with cloud cover were not used in this study. The characteristics of the imageries are described in Table1 below.

\subsection{Method}

Some of the imageries have stripe line error that were corrected using focal analysis before pre-processed. These pre-processing such as geometric, radiometric and atmospheric corrections which are a prerequisite for analysis of biophysical parameters were carried out using the equation supplied by the Landsat user's hand book, [18][19]. All the operation from importing the data to analysis of the data were carried out in the GIS and RS software, Erdas Imagine 2014 and ArcGIS 10.2.1 respectively.

In order to estimate the NDVI and SAVI of the Middle River Kaduna catchment, Erdas imaging 2014 and ArcGIS was used respectively. While Crop coefficient (KC) was determined based on the relation between $\mathrm{KC}$ and Normalize Difference Vegetation Index NDVI represented below (Eq. 1) which was used by [10] and evaluated by [11] using ArcGIS.

$K_{C}=\frac{1.2}{N D V I_{d v}}\left(N D V I-N D V I_{m n}\right)$

where; 1.2 is the maximum $\mathrm{Kc}, \mathrm{NDVI}_{\mathrm{dv}}$ is difference between minimum and maximum NDVI value for vegetation and $\mathrm{NDVI}_{\mathrm{mv}}$ is the minimum NDVI value for vegetation.

There are several statistical tools for trend and seasonal variation assessments, but the procedure for calculating the trends has been widely discussed by the scientific community. Broadly, two groups of mathematical tools are available to calculate these trends: parametric and nonparametric. Parametric trend tests are more powerful than nonparametric ones, but they require data to be independent and normally distributed [14]. Parametric (linear regression) statistical analyses was used in this study, using Microsoft Excel software.

\section{RESULTS AND DISCUSSION}

\subsection{Normalized Difference Vegetation Index (NDVI)}

The Normalized Difference Vegetation Index (NDVI) is a measure of the amount and strength of vegetation at the surface. The magnitude of NDVI is related to the level of photosynthetic activity in the observed vegetation.
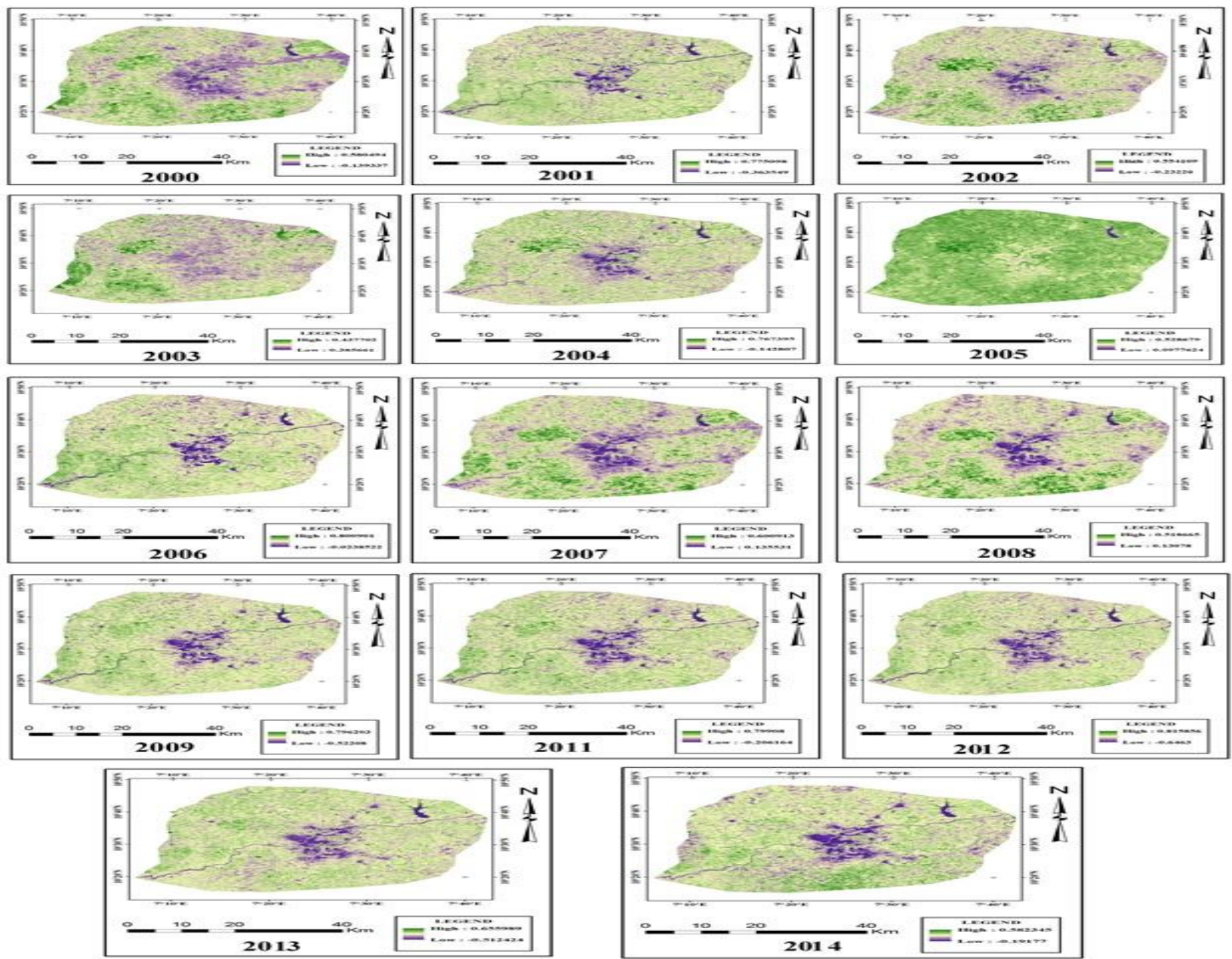

Figure 2. Spatio-temporal map of NDVI of middle river Kaduna catchment 
The NDVI maps were generated for the study area which revealed increased in spatial pattern towards the surrounding part of Middle river Kaduna catchment (Figure 2). The Apaka forest reserve situated in the North Western part of Middle River Kaduna catchment shows distinguished high NDVI. High values of NDVI indicate greater vigor, and amounts of vegetation [22]. Also, the South Western part of the Middle River Kaduna catchment area shows a high range of NDVI. Whereas, the Kangimi Dam in the North Eastern part of study area indicated Middle NDVI. In the central part of study area, where Kaduna metropolis is located also shows a low NDVI value. This indicated that the built up area have high NDVI value more than the water body.
This spatial pattern of NDVI is not the same for all the years. This implies that the spatio-temporal pattern of NDVI has been changed over time (Figure 3). The year 2002, NDVI of Middle River Kaduna catchment area was significantly low, this shows an absence of healthy vegetation. However, both the maximum, minimum, and mean value of 2003 shared close related NDVI. The NDVI for 2009, 2011, and 2012 shows a close related mean value, while 2013 and 2014 shows a depletion of vegetation covers which may be as a result of climatic condition [7, 22] such as decreased in rainfall in the Middle River Kaduna catchment area [1] and the intensified habitat desiccation [22].

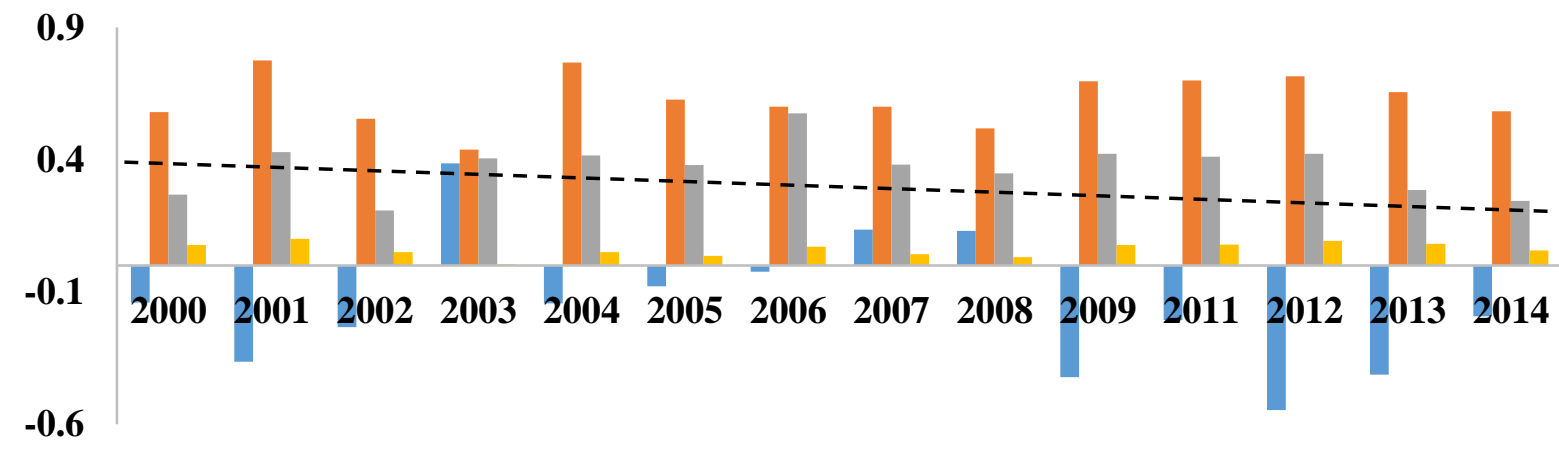

$\square \min \square \max \square \operatorname{mean} \square$ STDDEV

Figure 3. Time series of NDVI in Middle River Kaduna Catchment

Table 2. Coefficient of trend analysis of NDVI, SAVI and $\mathrm{KC}$

\begin{tabular}{lcc}
\hline INDICES & $\mathbf{a}$ & $\mathbf{b}$ \\
\hline NDVI & -0.0042 & 0.3608 \\
SAVI & -0.0015 & 0.2771 \\
KC & -0.0003 & 0.3304 \\
\hline
\end{tabular}

NDVI value over the time at which the images were taken shows a negative trend (Figure 3). Similar results was found in Pakistan by [23]. Therefore, this results has confirm the statement of [7] that NDVI is an indicator of the density of vegetated cover and plant vigour.

\subsection{Soil adjusted vegetation index (SAVI)}

SAVI is the Soil Adjusted Vegetation Index, which was introduced by [26]. It minimized soil influences and it shows the cover of the soil by canopy [26].

SAVI map were generated (Figure 5) which shows variation in Middle River Kaduna catchment area. The spatio-temporal pattern of SAVI coincides with the pattern of NDVI having higher values, where NDVI is high and vice versa. A higher proportion of SAVI indicates better canopy water content and healthy vegetation, whereas less SAVI is associated with water stressed vegetation tables and figures in the order mentioned in the text, at top or bottom of page, as close as possible to text reference.
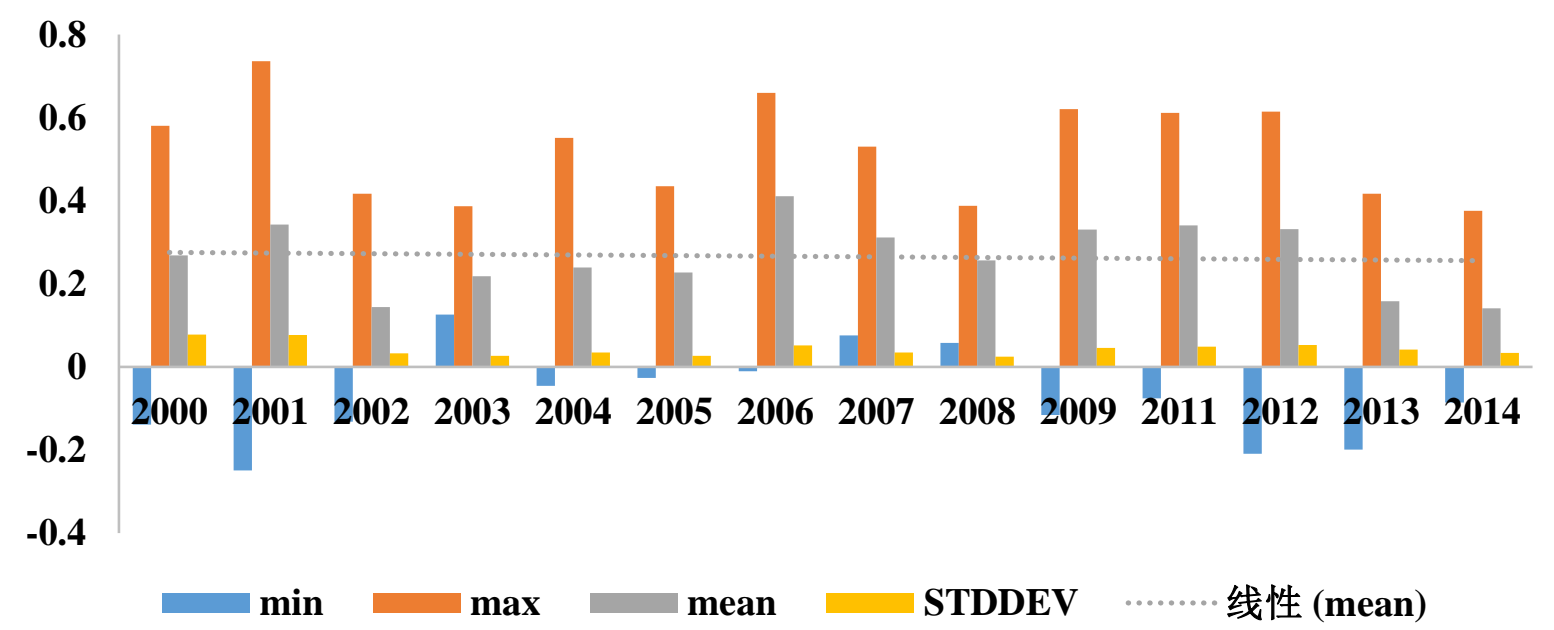

Figure 4. Time series of SAVI in Middle River Kaduna Catchment Area 

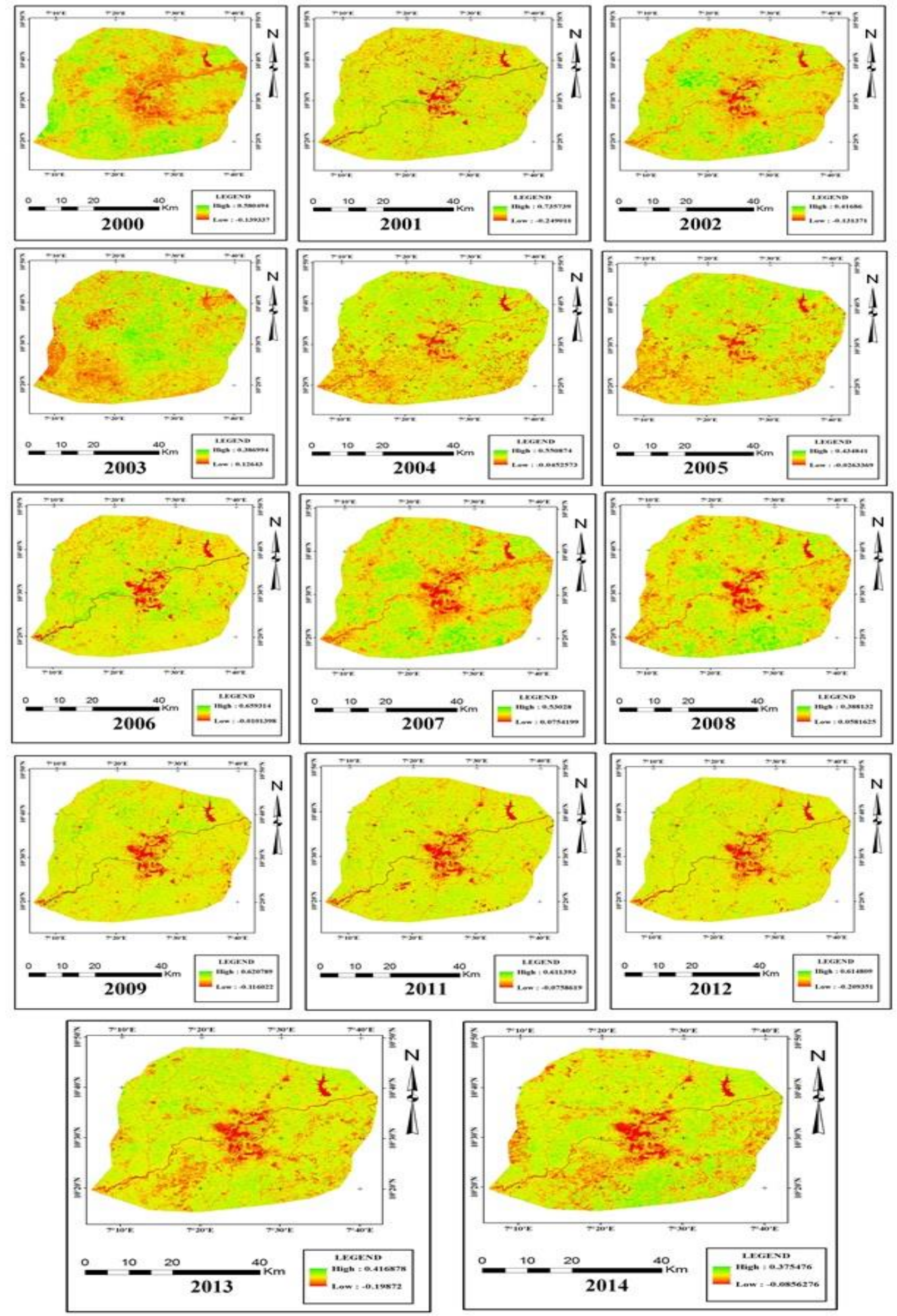

Figure 5. Spatio-Temporal map of SAVI of middle river Kaduna catchment 
When people tampered the ecosystem, values of SAVI is Middle than in natural habitat. Figure 4 shows that 2006 has the highest mean value, followed by 2001, while 2002, 2013, and 2014 has lowest value. Also it shows the negative trend of SAVI for Middle River Kaduna catchment area respectively.

Both the vegetation indices shown negative temporal trend (Table 2), this in line with the result of [21] and [16]. Therefore the two indices exhibited similar biophysical characteristic of Middle River Kaduna catchment area. These negative temporal trend indicate that there is decreased of vegetation in Middle River Kaduna catchment area over time. This can be associated with both natural and anthropogenic factors such as deforestation [3], bush burning, fire wood, clearance for cultivation and over grazing [21] and the persistent droughts in the Sudano-sahelian zone of Nigeria as recorded in 20s [20]. It clearly demonstrated a general tendency for a decreased in rainfall in the area [1]. The decreased of vegetation in Middle River Kaduna catchment area showed similarities with other studied such as [2] who studied land use/land cover change in TalataMafara, Oyinloye et al. (2003) who studied land use/land cover in Ilesha and that of [20] whose analysed the spatio-temporal dynamics of land use/ land cover structures' in the Kaduna inner core city region, Nigeria.

\subsection{Crop Coefficient (KC)}
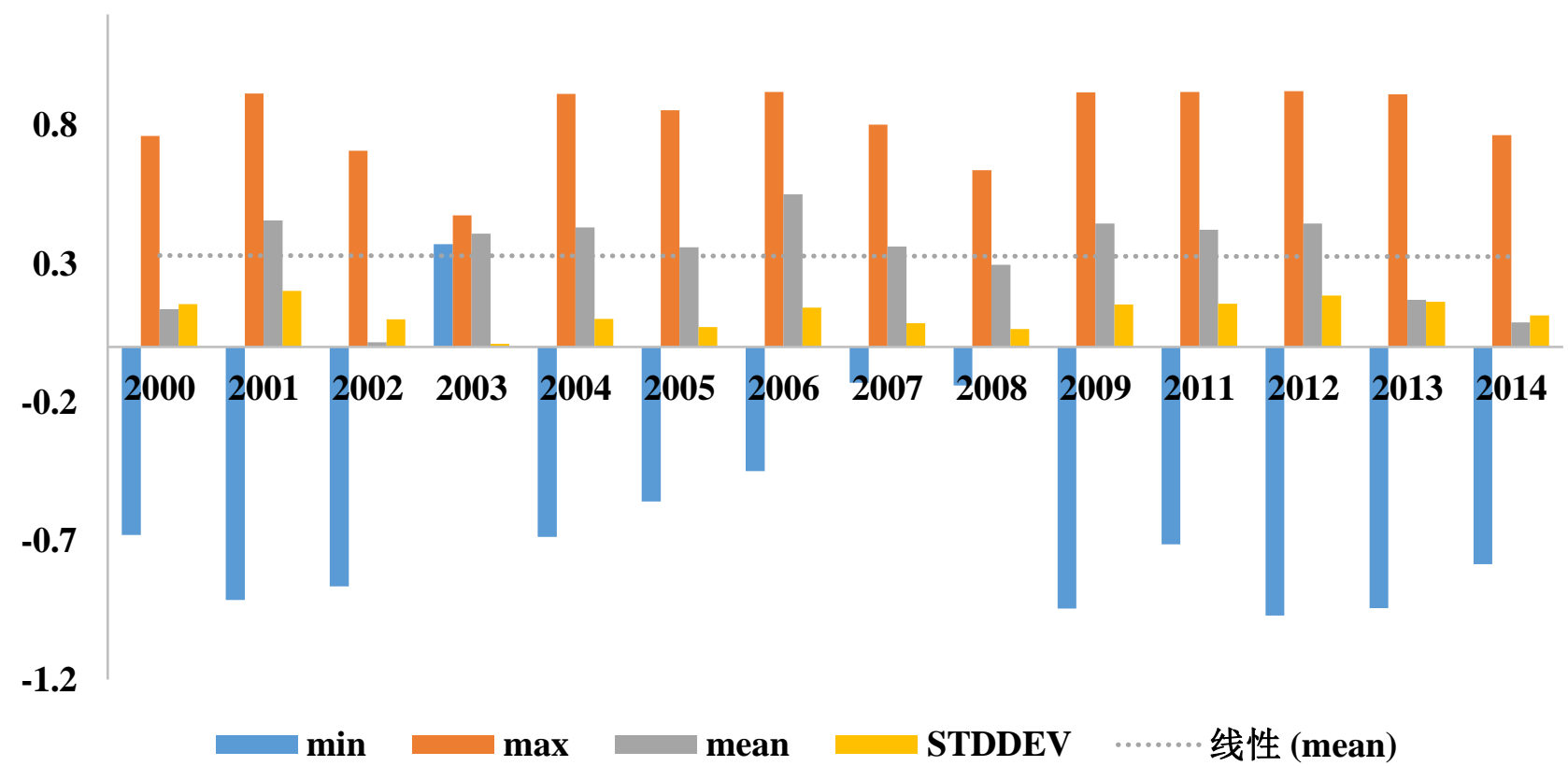

Figure 6. Time series of $\mathrm{KC}$ in middle river Kaduna catchment area

Figure 6 shows that the year 2006 has the highest mean value, followed by 2009 and 2001, while 2002 has the Middle value, followed by 2014. However, 2012 has the highest maximum and minimum KC value. The 2013 and 2011 have similar standard deviation value while 2003 has Middle standard deviation value, and 2001 has the highest value. The temporal trend analysis shows a negative trend of $\mathrm{KC}$ in Catchment Area (Table 2).

The spatio-temporal study of $\mathrm{KC}$ revealed that there is changed over time (Figure 7). Both the maximum, minimum, and the mean shared close related $\mathrm{KC}$ value in the year of 2003. The KC for the year of 2009, 2011, and 2012 also exhibited a close related mean value. More so, KC maps (Figure 7) were generated of study area which revealed the increased spatial pattern towards surrounding part from the centre i.e. Kaduna Metropolis of Middle River Kaduna catchment area. The Afaka forest reserve situated in the North Western part of Middle River Kaduna catchment showed distinguished high KC. The close spacing of plants and taller canopy height and roughness of many full grown Afaka forest reserve caused the plants to have maximum $\mathrm{KC}$ factors. Also the South Western part of the Middle River Kaduna catchment area shows high range of Kc, whereas, the Kangimi Dam in the North Eastern part of study area indicated Middle KC. In the central part of study area where Kaduna metropolis is located also showed a low $\mathrm{KC}$ value these is due to the natural surface converted to impervious surface which make the soil surface dry, and evaporation is restricted.

These shows a similar pattern of KC with NDVI. This implies that the NDVI as an indicator of the density of vegetated cover and plant vigour, therefore, it is not surprised that it captures most of the variation observed in $\mathrm{KC}$ [7]. The $\mathrm{KC}$ indicate that the influence of soil moisture on ET is less than that of surface net radiation, vegetation conditions (vegetation indices) and temperatures in vegetated regions.

These losses of vegetated cover lead to an increased dryness ratio during the period of study in the region. The consequences of the above are poor air quality, intense heat is experienced in the Middle River Kaduna catchment area due to high rate of evaporation in the absence of vegetation due to rapid urbanization taken place. High noise pollution is experienced in many parts of the metropolis [17]. More so, the absence of vegetation as wind-breaker result in the parking-off of roofing's and buildings during windstorms and high electrical energy is required to power electrical appliances such as fridge and air-condition to supplement natural cooling [17]. 

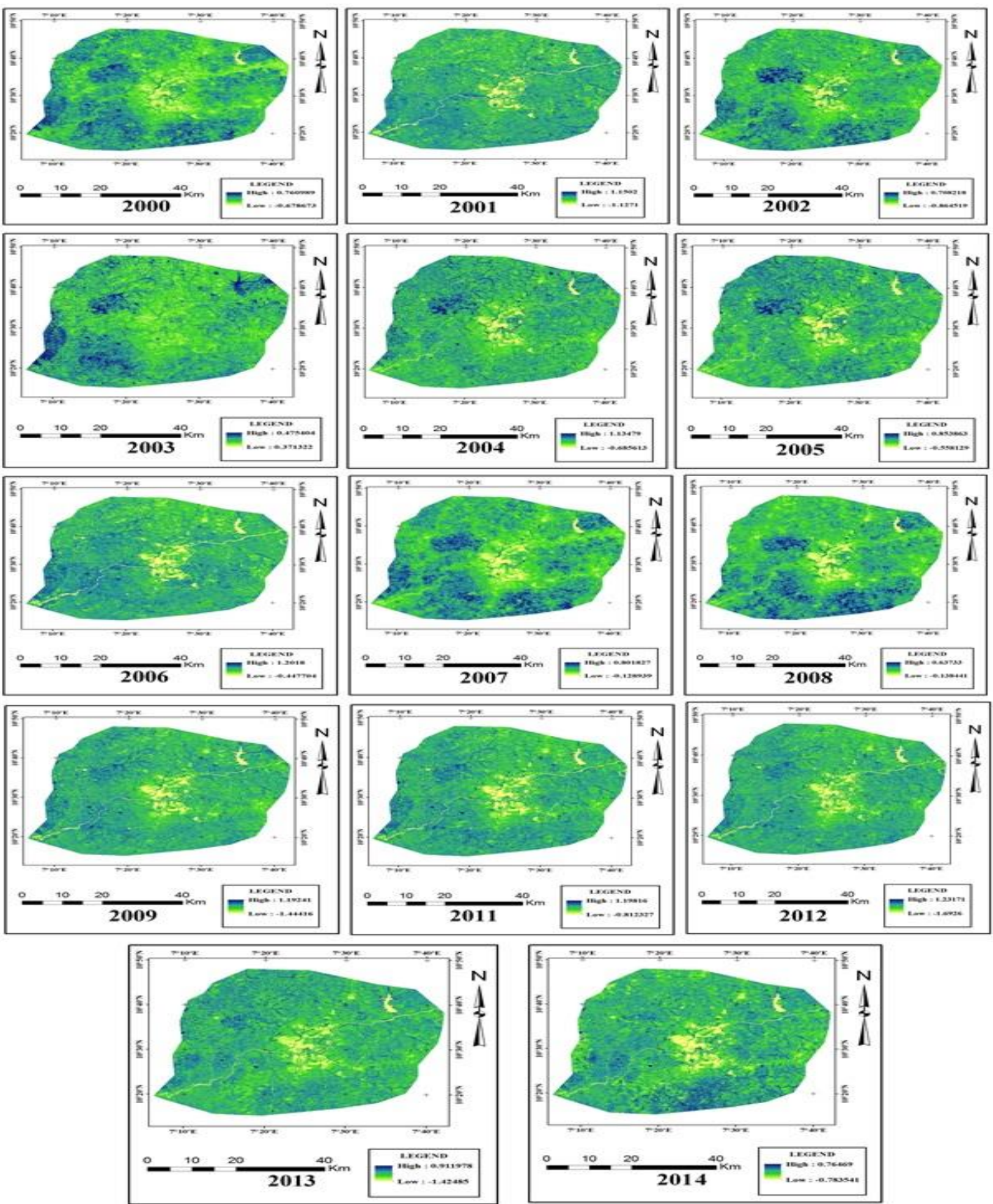

Figure 1. Spatio-temporal map of $\mathrm{KC}$ of middle river Kaduna catchment

\section{CONCLUSION}

This study clearly reveals that the importance of remote sensing tool in assessing vegetation condition. NDVI, SAVI and $\mathrm{Kc}$ showed a spatial and temporal variability in Middle Kaduna River Catchment area. The vegetation condition varied from one region to another. Also revealed that NDVI and SAVI are indicators of the density of vegetative cover and plant vigour. It captures most of the variation observed in $\mathrm{KC}$. If the present trend continues the vegetation may disappear in short time. From the results it can be concluded that cultivation, overgrazing, deforestation and improper land use can make the catchment area vulnerable to extreme event such as occurrence of flood and drought. And possible prevalence of land degradation in the catchment area [27].

\section{ACKNOWLEDGEMENT}

We sincerely thank USGS for providing free access to Landsat dataset. We also thank the reviewers for their valuable comments and useful suggestions. 


\section{REFERENCES}

[1] Abaje IB, Ishaya S, Usman SU. (2010). An analysis of rainfall trends in Kafanchan, Kaduna State, Nigeria. Research Journal of Environmental and Earth Sciences. 2(2): 89-96.

[2] Abubakar SM, Kudanmiya YR, Eyong PN. (2002). Assessment of environmental degradation using satellite remote sensing technologies in Talata Mafara Area, Northern Nigeria. Environmental Review 4(1): 577-586.

[3] Ajileye OO, Aigbiremolen IM, Mohammed SO, Halilu AS, Alaga AT. (2016). Effect of climatic variability on drought occurrence probability over Nigeria. British Journal of Applied Science and Technology 12(1): 1-13.

[4] Ali IN. (2013). Fuel wood and vegetation change in Northern Nigeria: An exploration using remote sensing (RS), geographical information systems (GIS) and field reports. Unpublished $\mathrm{PhD}$ Thesis. University of Portsmouth, UK.

[5] Ati OF, Tabitha Sheyin, Innocent Abbas, Seidu O, Mohammed. (2010). Assessing changes in Kagoro Forest, Kaduna State Nigeria using remote sensing and GIS. Res. J. Appl. Sci. Eng. Technol. 2(2): 121-132.

[6] Audu EB. (2013). Fuel wood consumption and desertification in Nigeria. International Journal of Science and Technology 3(1): 1-5.

[7] Baburao K, Ayse K, Kenneth H. (2013). Estimating crop coefficients using remote sensing-based vegetation index. Remote Sens. 5: 1588-1602. http//doi.org/103390/rs5041588

[8] Zaharaddeen I, Mohammed SO, Auwal FA, Abel GR. (2017). Estimation of biophysical properties in lower river Kaduna catchment area Kaduna, Nigeria. Asian Journal of Environment and Ecology (AJEE) 4(1): 1-13. http//doi.org/10.9734/AJEE/2017/32960

[9] Benkouider F, Abdellaoui A, Hamami L, Elaihar M. (2013). Spatio temporal analysis of vegetation by vegetation indices from multi-dates satellite images: Application to a semi-arid area in Algeria. Energy Procedia 36: 667-675.

[10] El-Shirbeny MA, Aboelghar MA, Arafat SM, El-Gindy AG. (2014). Assessment of the mutual impact between climate and vegetation cover using NOAA-AVHRR and Landsat data in Egypt. Arabian Journal of Geosciences 7(4): 1287-1296.

[11] El-Shirbeny MA, Ali AM, Badra MA, Bauomy EM. (2014). Assessment of wheat crop coefficient using remote sensing techniques. World Research Journal of Agricultural Sciences 1(2): 12-17.

[12] Musa HD, Bukar S. (2010). Integrated remote sensing approach to desertification monitoring in the croprangeland area of Yobe State, Nigeria. Journal of Sustainable Development in Africa 12(5): 236-250.

[13] Hatton T. (2001). Land use and catchment water balance. Technical Report 18/01. CSIRO Land and Water.

[14] Hossein T, Ali A, Hossein ZPT, Shifteh SB. (2011). Spatial distribution and temporal variation of reference evapotranspiration in arid and semi-arid regions of Iran. Hydrol. Process 814: 1-13.

[15] Justice CO, Townshend JRG. (2002). Special issue on the moderate resolution imaging spectroradiometer
(MODIS): A new generation of land surface monitoring. Remote Sens. Environ 83: 1-2.

[16] Kinthada NR, Gurram MK, Eadara A, Velagala VR. (2014). Land use/ land cover and NDVI analysis for monitoring the health of micro-watersheds of sarada river basin, Visakhapatnam District, India. J Geol Geosci 3: 146. http//doi.org/10.4172/2329-6755.1000146

[17] Mohammed AA, Aliyu DG. (2014). Urban Vegetation Study of Kaduna Metropolis using GIS and remotely sensed Data. Journal of Natural Sciences Research 4(2): 160-171.

[18] NASA. Landsat 7 Science Data Users Handbook (United States). https://landsat.gsfc.nasa.gov/wpcontent/uploads/2016/08/Landsat7_Handbook.pdf

[19] NASA. Landsat 8 Science Data Users Handbook (United States).

https://landsat.usgs.gov/documents/Landsat8DataUsers Handbook.pdf

[20] Ndabula C, Averik PD, Jidauna GG, Abaje I, Oyatayo TK, Iguisi EO. (2013). Analysis of the Spatio-temporal dynamics of land use/ land cover structures in the kaduna inner core city region, Nigeria. American Journal of Environmental Protection 1(4): 112-119. http//doi.org/10.12691/env-1-4-7

[21] Chris N. (2006). Assessment of land use/Landover changes in Kaduna Metropolitan area using remote sensing and geographic information system techniques. Unpublished Msc Thesis, Abu Zaria.

[22] Ogutu JO, Piepho HP, Dublin HT, Bhola N, Reid RS. (2007). El Nin $\sim$ o-southern oscillation, rainfall, temperature and normalized difference vegetation index fluctuations in the mara-serengeti ecosystem. Afr. J. Ecol. 46: $132-143$.

[23] Syeda RS, Amjed A, Ashfaq A, Muhammad M, Zia-UlHaq M, Shakeel A, Sezai E, Hawa ZEJ. (2014). Normalized difference vegetation index as a tool for wheat yield estimation: A case study from Faisalabad, Pakistan. Scientific World Journal 725326: 8. http://dx.doi.org/10.1155/2014/725326

[24] Taiye OA, Emmanuel AO. (2015). Sustainability of fuel wood harvesting from Afaka forest reserve, Kaduna State, Nigeria. Journal of Agricultural Science 7(1): 129-135. http://dx.doi.org/10.5539/jas.v7n1p129

[25] Zaharaddeen I. (2017). Assessment of Spatio-Temporal variation of Evapotranspiration in Middle River Kaduna Catchment area, Nigeria. Unpublished M.Sc. Thesis, Department of Geography Kaduna State University 1113.

[26] Huete AR. (1988). A soil-adjusted vegetation index (SAVI). Remote Sensing of Environment 25: 295-309.

[27] Liu Y, Wang J. (2015). The research and application of landslide surface crack monitoring method based on laser ranging mode. Environmental and Earth Sciences $\begin{array}{lll}\text { Research Journal } & 2(2) \text { : } & 19-24\end{array}$ http://dx.doi.org/10.18280/eesrj.020204

[28] Yang G, Song G, Cui W, Baiyinbaoligao, Chen W. (2015). Analysis and evaluation of land use and landscape pattern changes in Caohai watershed. Environmental and Earth Sciences Research Journal 2(2): 1-6. http://dx.doi.org/10.18280/eesrj.020201 